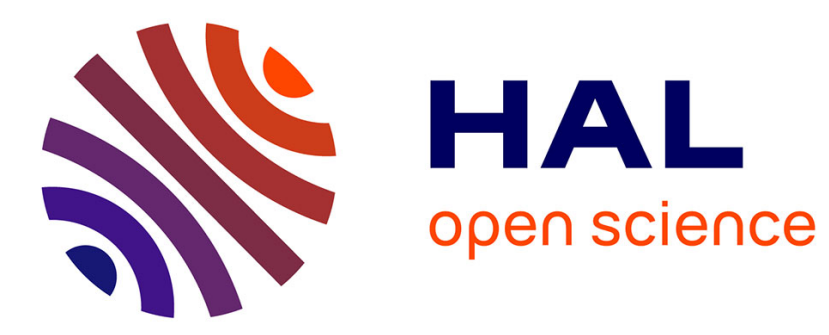

\title{
High-resolution on-chip supercapacitors with ultra-high scan rate ability
}

\author{
Ty Mai Dinh, Kevin Armstrong, Daniel Guay, David Pech
}

\section{To cite this version:}

Ty Mai Dinh, Kevin Armstrong, Daniel Guay, David Pech. High-resolution on-chip supercapacitors with ultra-high scan rate ability. Journal of Materials Chemistry A, 2014, 2 (20), pp.7170 - 7174. $10.1039 / \mathrm{c} 4$ ta00640b . hal-01874490

\section{HAL Id: hal-01874490 \\ https://hal.laas.fr/hal-01874490}

Submitted on 14 Sep 2018

HAL is a multi-disciplinary open access archive for the deposit and dissemination of scientific research documents, whether they are published or not. The documents may come from teaching and research institutions in France or abroad, or from public or private research centers.
L'archive ouverte pluridisciplinaire HAL, est destinée au dépôt et à la diffusion de documents scientifiques de niveau recherche, publiés ou non, émanant des établissements d'enseignement et de recherche français ou étrangers, des laboratoires publics ou privés. 


\title{
High-resolution on-chip supercapacitors with ultra- high scan rate ability
}

\author{
Ty Mai Dinh, ${ }^{a b}$ Kevin Armstrong, ${ }^{c}$ Daniel Guay ${ }^{c}$ and David Pech ${ }^{* a b}$
}

\begin{abstract}
A simple approach for the fabrication of high-resolution onchip supercapacitors with increased performances is demonstrated. The resulting micro-devices display high specific cell capacitance $\left(3 \mathrm{mF} \mathrm{cm}^{-2}\right.$ using hydrous ruthenium oxide electrode) and impressive scan rate abilities, up to $10000 \mathrm{~V} \mathrm{~s}^{-1}$ for multi-walled carbon nanotubes based microsupercapacitors, which is five orders of magnitude higher than conventional supercapacitors.
\end{abstract}

The tremendous push towards systems on chip (SoC) approach together with the decrease of their dimensions has enabled the development of new applications such as wireless sensors network or wearable devices that can be integrated into everyday-use objects. As microelectronic devices get smaller and smaller, it has become critical to power them with micro-power sources of appropriate size, fulfilling specific requirements for self-powered applications such as long lifetime and high-rate charge/discharge capabilities. Electrochemical capacitors (also called supercapacitors) show very interesting characteristics when it comes to these applications, because of their extended lifetimes and high power densities. Supercapacitors store electrical energy using the electrochemical double layer formed at the electrode/electrolyte interface (electrochemical double layer capacitance) or the very fast and reversible electrochemical reaction of some materials deposited at the surface of an electrode (pseudo-capacitance). ${ }^{1,2}$ The realization of on-chip micro-sized supercapacitors could satisfy a variety of micro- power demands and embedded microsystems. ${ }^{3}$

We have recently shown that the power ability of microsupercapacitors can be dramatically improved by reducing the physical separation between the anode and the cathode. ${ }^{4,5}$ Indeed, an optimized configuration with very high resolution patterns should considerably increase the performances of micro-supercapacitors (capacitance, energy and power normalized to its footprint area on the chip) due to reduced ohmic losses, better impregnation by the electrolyte, higher accessibilities and compactness. However, most of "micro-supercapacitors" reported in literature have resolution above $100 \mu \mathrm{m}$, the term "micro" referring mainly to the microfabrication techniques used for their fabrication. ${ }^{6-11}$ Regardless of the deposition technique, the common challenge is to deposit porous materials on micro-sized substrates without shorting the positive and negative electrodes. ${ }^{12}$

Here, we demonstrate a new and simple approach for large-scale fabrication of micro-supercapacitors with resolution (i.e. spacing between interdigitated fingers) down to the limit of standard photolithography, i.e. $1 \mu \mathrm{m}$ (see Fig. S1 in ESI $\dagger$ ). The process has been successfully applied for the realization of electric double-layer micro-capacitors ( $\mu$-EDLCs) based on multi-walled carbon nanotubes (MWCNTs), and pseudo-capacitive electrochemical micro-capacitors ( $\mu$-SCs) based on hydrated ruthenium oxide $\left(\mathrm{hRuO}_{2}\right)$. The resulting micro-supercapacitors exhibit excellent electrochemical performances with specific cell capacitance up to $3 \mathrm{mF} \mathrm{cm}{ }^{-2}$ for $\mathrm{hRuO}_{2}$ and life cycle exceeding 30000 cycles for MWCNTs. All micro-devices display also, impressive scan rate abilities, up to $10000 \mathrm{~V} \mathrm{~s}^{-1}$ for MWCNTs, which is five orders of magnitude higher than conventional supercapacitors. The proposed strategy is promising for batch fabrication and integration of operational on-chip micro-supercapacitors into existing micro systems. With electron beam or nano-imprint lithography, the process could also be used for the realization of nanosupercapacitors with sub-micrometer pattern resolutions.

The basic idea for the realization of $\mu$-SCs with high resolution is illustrated in Fig. 1a,b. Current collectors ( $\mathrm{Ti} / \mathrm{Au}$ in this case) were first patterned onto an oxidized silicon wafer and protected by an insulating SU8 masking layer using conventional photolithography techniques. We focused, then, on a lift-off process to realize the micro-devices. This is a widely used method for transferring patterns from resist layers to the material to be structured. In our case, we used this technique to pattern, with high resolution, the current collectors as well as the active material. ${ }^{13}$ The material deposition was then facilitated as it occurs at wafer level, which is the key to batch fabrication of functional materials on chips. Most importantly, however, this method avoids the necessity to deposit the electrode material onto micro-sized patterned current collectors - which often leads to deposition on unwanted areas. We validated the process down to $1 \mu \mathrm{m}$ using two different deposition techniques: the 
electrophoretic deposition of MWCNTs and the electrolytic deposition of $\mathrm{hRuO}_{2}$ (see Fig. S2 in ESI $\dagger$ ). For practical reasons, the micro-devices were realized with a $10 \mu \mathrm{m}$ interspace. For both materials, an adherent layer was obtained with a well-defined pattern, without any short circuit between the electrodes (Fig. 1c,d). The thicknesses, which can be easily modulated by controlling the time used for the electrodeposition of the active layer, were 260 and $100 \mathrm{~nm}$ for MWCNTs and $\mathrm{hRuO}_{2}$, respectively. As illustrated in Fig. 2 , this process has overcome resolution limits for the integration of active materials into micro-fabrication technologies, with one of the smallest resolution ever to be applied for "micro-supercapacitor" applications. ${ }^{14-17}$ We have investigated the influence of such resolutions on the performances of $\mu$-SCs.

Cyclic voltammograms (CVs) were recorded at scan rates ranging from 0.05 to $10000 \mathrm{~V} \mathrm{~s}^{-1}$ in a de-aerated $0.5 \mathrm{M} \mathrm{H}_{2} \mathrm{SO}_{4}$ electrolyte to evaluate the power capability of the micro-devices. The microsupercapacitors of both materials display the rectangular shape voltammograms expected for double layer and pseudo-capacitive materials. The symmetrical capacitive behavior was maintained up to an ultrafast scan rate of $10 \mathrm{~V} \mathrm{~s}^{-1}$ for the $\mathrm{hRuO}_{2}$-based $\mu$-SC (see Fig. S3 in ESI $\dagger$ ), and to an impressive value of $1000 \mathrm{~V} \mathrm{~s}^{-1}$ for the MWCNTs-based $\mu$-SC (Fig. 3). The MWCNTs micro-sized device was even able to cycle at an ultrafast scan rate of $10000 \mathrm{~V} \mathrm{~s}^{-1}$, which is more than five orders of magnitude higher than conventional supercapacitors, and, to the best of our knowledge, the highest value ever reported for micro-supercapacitors. ${ }^{4,18-21}$ The specific capacitances were 0.2 and $3.2 \mathrm{mF} \mathrm{cm}^{-2}$ at $10 \mathrm{~V} \mathrm{~s}^{-1}$ for the MWCNTs and the $\mathrm{hRuO}_{2}$-based $\mu$-SCs, respectively. These values are comparable to the specific capacitances reported in the literature at much lower scan rates for $\mu$-EDLCs $\left(0.4-1.5 \mathrm{mF} \mathrm{cm}^{-2}\right)^{22-24}$ and pseudo-capacitive $\mu$-SCs $\left.\left(0.4-12.6 \mathrm{mF} \mathrm{cm}^{-2}\right)\right)^{5,12,25}$ The high scan rate, representative of a high instantaneous power, is thus concomitant with a high specific capacitance. This ability to cycle at such scan rates is due to the very low value of the time constant $(\tau)$ of the interdigitated micro-supercapacitors ( $\tau=R C$, where ' $C$ ' is the cell capacitance and ' $R$ ' is the equivalent series resistance, ESR), thanks to their very high resolution pattern.

To highlight the beneficial effect of the resolution on the power performance, we have simulated the influence of the interspace $(i)$ between the electrodes of planar interdigitated $\mu$-SCs on their time constant $(\tau)$, according to the following equation:

$$
\boldsymbol{\tau}=\left(\boldsymbol{R}_{c c}+\mathrm{K} \times \rho_{e}\right) \boldsymbol{C}
$$

with $R_{c c}$ the resistance of the current collectors, $\rho_{e}$ the resistivity of the electrolyte and $K$ the analytical expression of the cell constant developed by W. Olthuis et al. ${ }^{5,26}$

As shown in Fig. 4a, a micro-scale reduction of the interspace between adjacent fingers (of $100 \mu \mathrm{m}$ width and $1000 \mu \mathrm{m}$ length) significantly reduces the contribution of the ESR and consequently, the time constant $(\tau)$ is diminished. The corresponding simulations of the $\mathrm{CV}$ curves at $1000 \mathrm{~V} \mathrm{~s}^{-1}$ for various time constants, according to the equations developed by B.E. Conway, ${ }^{27}$ are shown Fig. 4 b. We can clearly see that the CVs of the high resolution microsupercapacitors can keep a rectangular shape at scan rates $(s)$ exceeding $1000 \mathrm{~V} \mathrm{~s}^{-1}$. It is noteworthy that the scan rate ability only depends on the $R C$ time constant.
Fig. 5a,b shows the Nyquist and Bode plots of the MWCNTsbased $\mu$-SC from $100 \mathrm{kHz}$ to $10 \mathrm{mHz}$. No leakage current is observed, with the near-vertical straight line (in the low-frequency region) typical of a capacitive material. A negligible equivalent distributed resistance EDR (due to the thin thickness of the active material) and a very low ESR of $0.16 \Omega \mathrm{cm}^{2}$ were estimated from the high frequency part of the spectrum. As the specific power will predominantly depend on the highest resistive contribution between the ESR and the EDR, the influence of the resolution of the configuration of the micro-device is prominent, in this case, with a maximum specific power of $1.3 \mathrm{~W} \mathrm{~cm}^{-2}$. Taking into account the capacitance, the MWCNTs-based $\mu$-SC is characterized by an extremely low time constant $(\tau)$ of $32 \mu \mathrm{s}\left(512 \mu \mathrm{s}\right.$ for the $\mathrm{hRuO}_{2}$ based $\mu$-SC, see Fig. S4 in ESI $\dagger$ ), which is in complete agreement with the theoretically determined values.

The electrochemical stability of the deposited layers was finally investigated (Fig. 6 and Fig. S5 in ESI $\dagger$ ). The capacitance slightly increases after 30000 cycles at $1 \mathrm{~V} \mathrm{~s}^{-1}$ for the $\mu$-EDLC, due to a better electrolyte impregnation with time and cycling.

In conclusion, we have realized high-energy microsupercapacitors based on hydrated ruthenium oxide, and ultrahighpower micro-supercapacitors based on multi-walled carbon nanotubes using a simple and integrated-circuits-compatible approach for the deposition of the active material, with extremely high resolutions. This process can be applied to other materials or other deposition techniques. The micro-devices offer truly outstanding performances, with discharge rates of up to $10000 \mathrm{~V} \mathrm{~s}^{-1}$. The use of conventional UV-photolithography techniques $(1 \mu \mathrm{m}$ resolution) currently limits the size of the pattern, but further work will consider using this process with the stepper projection lithography (350 $\mathrm{nm}$ resolution) and electron beam lithography (sub$10 \mathrm{~nm}$ resolution) for further reduction of the interspace. In turn, these improvements in electrode design should lead to unprecedented performances of micro-supercapacitors.

\section{Acknowledgements}

This work was partly supported by the French RENATECH network and financially supported by the French National Research Agency (ANR) through the MIDISTOCK project. T.M. Dinh was supported by a $\mathrm{PhD}$ grant and a travel fellowship (ATUPS) from the Université de Toulouse. Collaborations between LAAS and INRS were supported by the Commission Permanente de Coopération FrancoQuébécoise (CPCFQ).

\section{Notes and references}

\footnotetext{
${ }^{a}$ CNRS, LAAS, 7 avenue du colonel Roche, F-31400 Toulouse, France. Email: dpech@laas.fr; Fax: +33 5613362 08; Tel: +33 561336837

${ }^{b}$ Univ de Toulouse, LAAS, F-31400 Toulouse, France.

${ }^{c}$ INRS-Énergie, Matériaux, Télecommunications, 1650 boulevard Lionel Boulet, J3X 1S2, Québec, Canada.
} 
1 P. Simon and Y. Gogotsi, Nat. Mater., 208, 7, 845-854.

2 S. Chen, W. Xing, J. Duan, X. Hu and S.Z. Qiao, J. Mater. Chem. A, 2013, 1, 2941-2954.

3 M. Beidaghi and Y. Gogosti, Energy Environ. Sci, 2014, 7, 867-884.

4 D. Pech, M. Brunet, H. Durou, P. Huang, V. Mochalin, Y. Gogotsi, P.L. Taberna and P. Simon, Nat. Nanotechnol., 2010, 5, 651-654.

5 D. Pech, M. Brunet, T.M. Dinh, K. Armstrong, J. Gaudet and D. Guay, J. Power Sources, 2013, 230, 230-235.

6 K. Wang, W. Zou, B. Quan, A. Yu, H. Wu, P. Jiang and Z. Wei, Adv. Energy Mater., 2011, 1, 1068-1072.

7 W. Gao, N. Singh, L. Song, Z. Liu, A.L.M. Reddy, L. Ci, R. Vajtai, Q. Zhang, B. Wei and P.M. Ajayan, Nat. Nanotechnol., 2011, 6, 496500 .

8 L. Cao, S. Yang, W. Gao, Z. Liu, Y. Gong, L. Ma, G. Shi, S. Lei, Y. Zhang, S. Zhang, R. Vajtai and P.M. Ajayan, Small, 2013, 9, 29052910.

9 M.F. El-Kady and R.B. Kaner, Nat. Comm., 2013, 4, 1475.

10 J. Lin, C. Zhang, Z. Yan, Y. Zhu, Z. Peng, R.H. Hauge, D. Natelson and J.M. Tour, Nano Lett., 2013, 13, 72-78.

11 W. Liu, X. Yan, J. Chen, Y. Feng and Q. Xue, Nanoscale, 2013, 5, 6053-6062.

12 S. Makino, Y. Yamauchi and W. Sugimoto, J. Power Sources, 2013, 227, 153-160.

13 E.T.T Jones, O.M. Chyan and M.S. Wrighton, J. Am. Chem. Soc., 1987, 109, 5526-5528.

14 B. Hsia, M.S. Kim, M. Vincent, C. Carraro and R. Maboudian, Carbon, 2013, 57, 395-400.

15 M. Beidaghi and C. Wang, Adv. Funct. Mater., 2012, 22, 4501-4510.

16 C. Shen, X.H. Wang, S. Li, J. Wang, W. Zhang and F. Kang, J. Power Sources, 2013, 234, 302-309.

17 C.H. Chen, D.S.Tsai, W.H. Chung, K.Y. Lee, Y.M. Chen and Y.S. Huang, J. Power Sources, 2012, 205, 510-515.

18 K. Sheng, Y. Sun, C. Li, W. Yuan and G. Shi, Sci. Rep., 2012, 2, 247.

19 A. Ghosh, V.T. Le, J.J. Bae and Y.H. Lee, Sci. Rep., 2013, 3, 2939.

20 Z.-S. Wu, K. Parvez, X. Feng and K. Müllen, Nat. Comm., 2013, 4, 2487.

21 W.-W. Liu, Y.-Q. Feng, X.-B. Yan, J.-T. Chen and Q.-J. Xue, $A d v$. Funct. Mater., 2013, 23, 4111.

22 D. Pech, M. Brunet, P.-L. Taberna, P. Simon, N. Fabre, F. Mesnilgrente, V. Conédéra and H. Durou, J. Power Sources, 2010, 195, 1266-1269.

23 P. Huang, M. Heon, D. Pech, M. Brunet, P.-L. Taberna, Y. Gogotsi, S. Lofland, J.D. Hettinger and P. Simon, J. Power Sources, 2013, 225, 240-244.

24 P. Huang, D. Pech, R. Lin, J.K. McDonough, M. Brunet, P.-L. Taberna, Y. Gogotsi and P. Simon, Electrochem. Comm., 2013, 36, 53-56.

25 C.-C. Liu, D.-S. Tsai, D. Susanti, W.-C. Yeh, Y.-S. Huang and F.-J. Liu, Electrochim. Acta, 2010, 55, 5768-5774.

26 W. Olthuis, W. Streekstra and P. Bergveld, Sens. Actuator B, 1995, 24-25, 252-256.

27 W.G. Pell and B.E. Conway, J. Power Sources, 2001, 96, 57-67. 
(a)
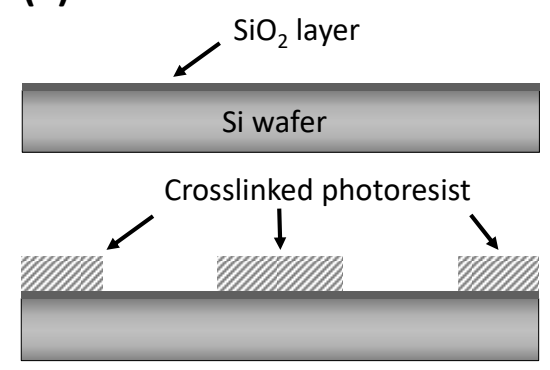

Ti/Au deposition

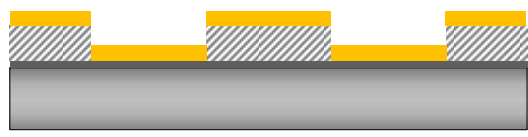

$\mathrm{hRuO}_{2}$ electrodeposition

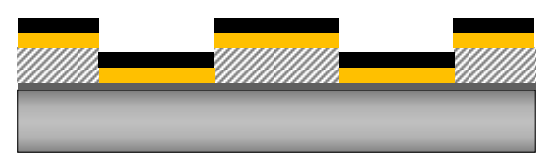

Lift-off

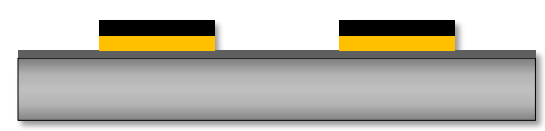

(b)

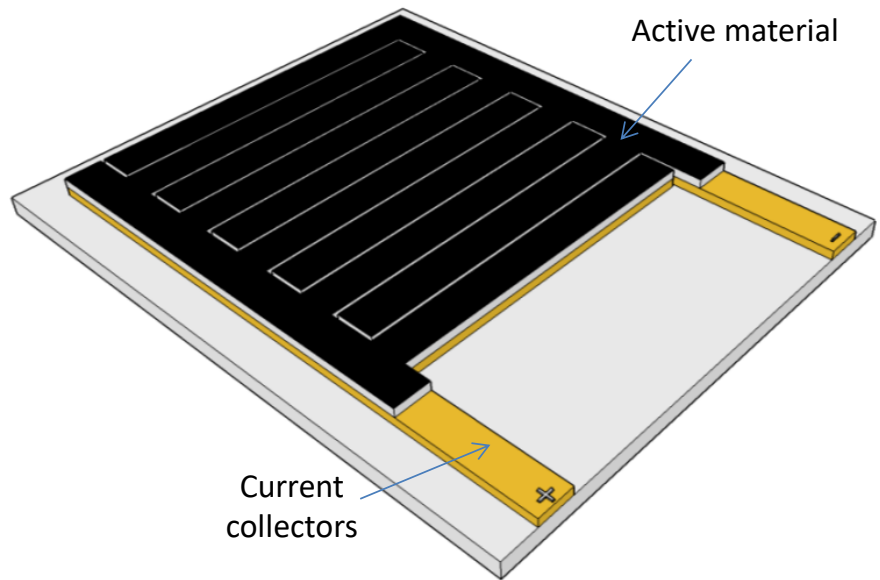

(d)

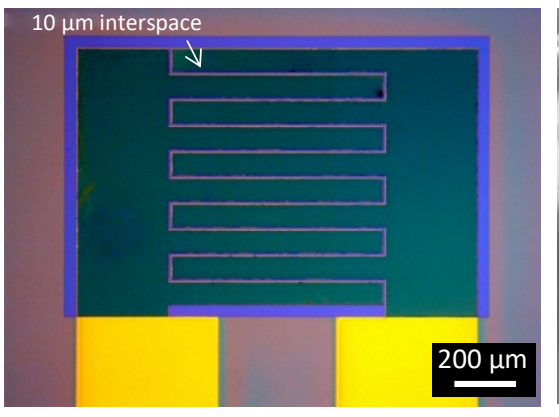

Fig. 1 Micro-supercapacitor fabrication and design. (a) Simplified illustration of the fabrication process using the lift-off process of the active material for high-resolution pattern (not to scale). Schematic (b) and optical image (c) of the micro-device. (d) Scanning electron microscope image of the cross-section of the electrode.

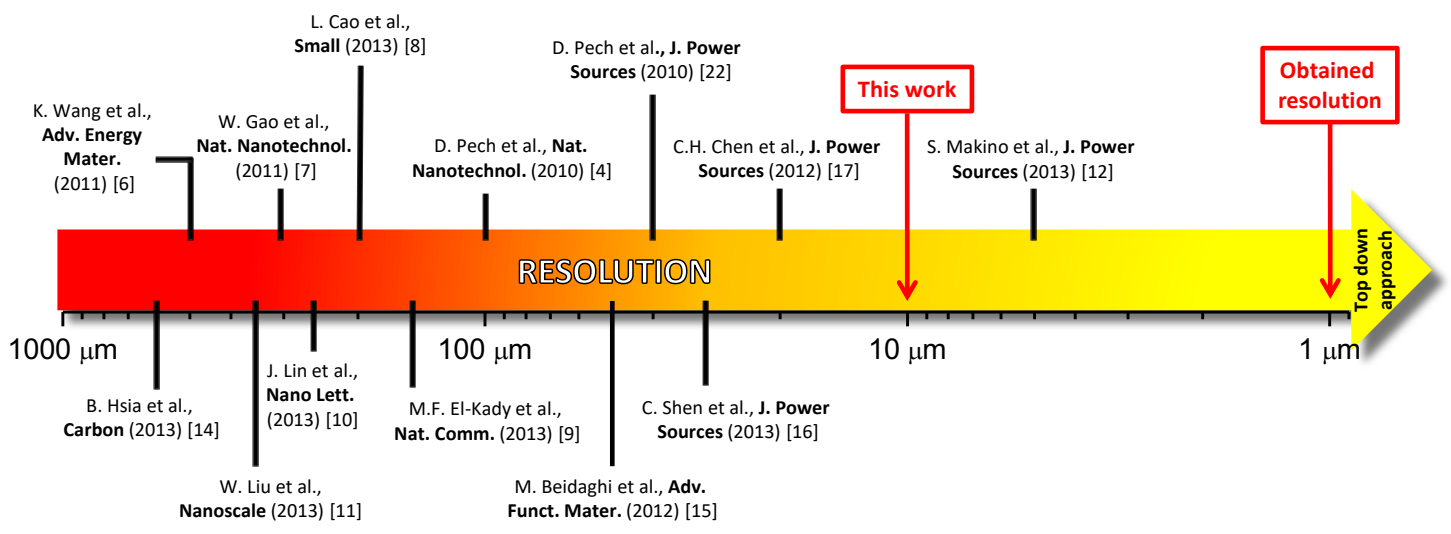

Fig. 2 Comparison of the resolution of state-of-the-art micro-supercapacitors reported in literature. 
(a)

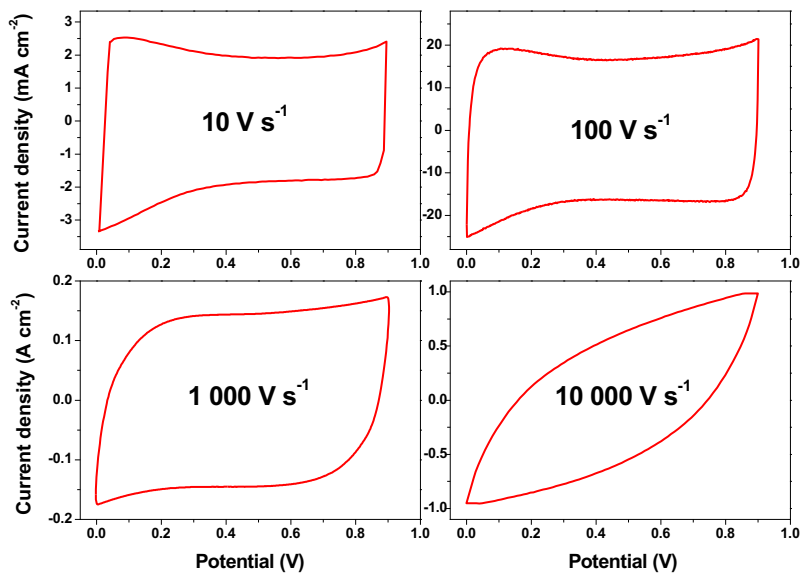

(b)

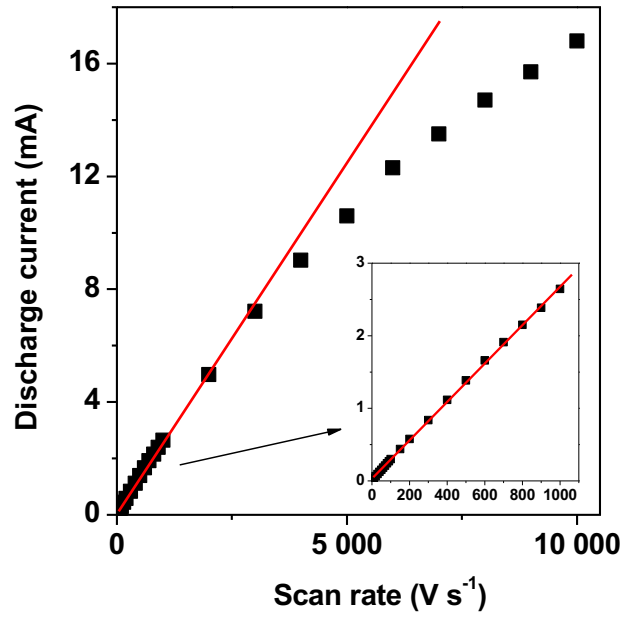

Fig. 3 Cyclic voltammetry charaterizations (CV) of MWCNTs-based micro-supercapacitor. (a) CVs obtained at different scan rates in de-aerated $0.5 \mathrm{M} \mathrm{H}_{2} \mathrm{SO}_{4}$ electrolyte. (b) Evolution of the discharge current versus scan rate.

(a)

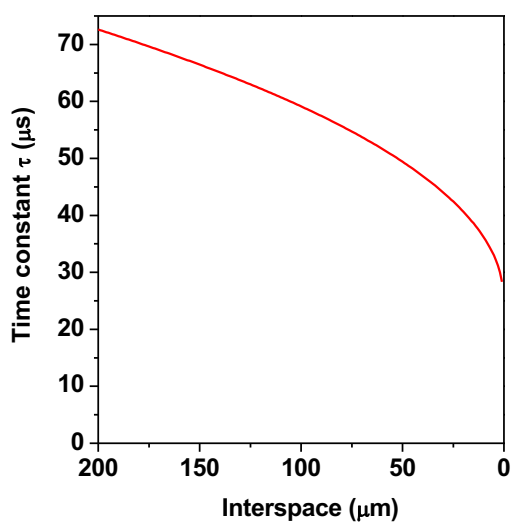

(b)

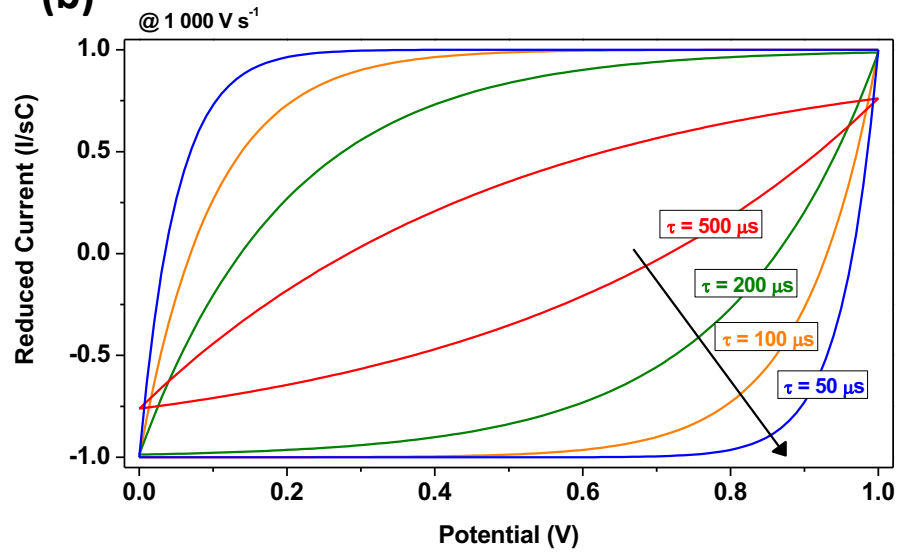

Fig. 4 (a) Theoretical evolution of the time constant $\tau$ of MWCNTs-based microsupercapacitor as a function of the distance between adjacent interdigitated electrodes in $0.5 \mathrm{M}$ $\mathrm{H}_{2} \mathrm{SO}_{4}$. (b) Calculated cyclic voltammograms expressed as reduced response current $(\mathrm{I} / \mathrm{sC})$ at $1000 \mathrm{~V} \mathrm{~s}^{-1}$ for various time constant. 
(a)

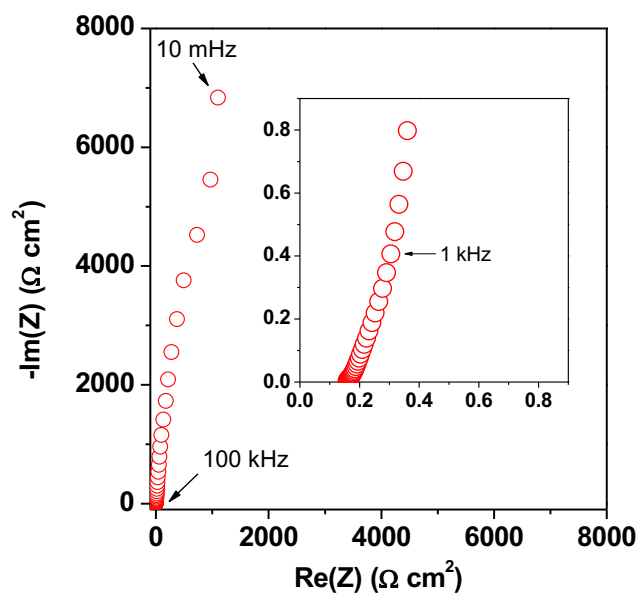

(b)

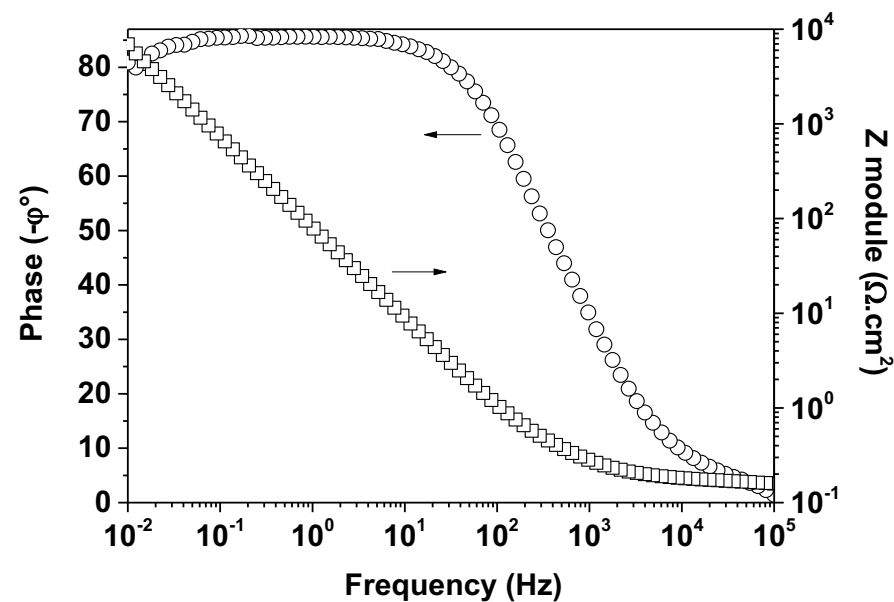

Fig. 5 (a) Nyquist and (b) Bode plots obtained from a MWCNTs-based micro-supercapacitor in $0.5 \mathrm{M} \mathrm{H}_{2} \mathrm{SO}_{4}$.

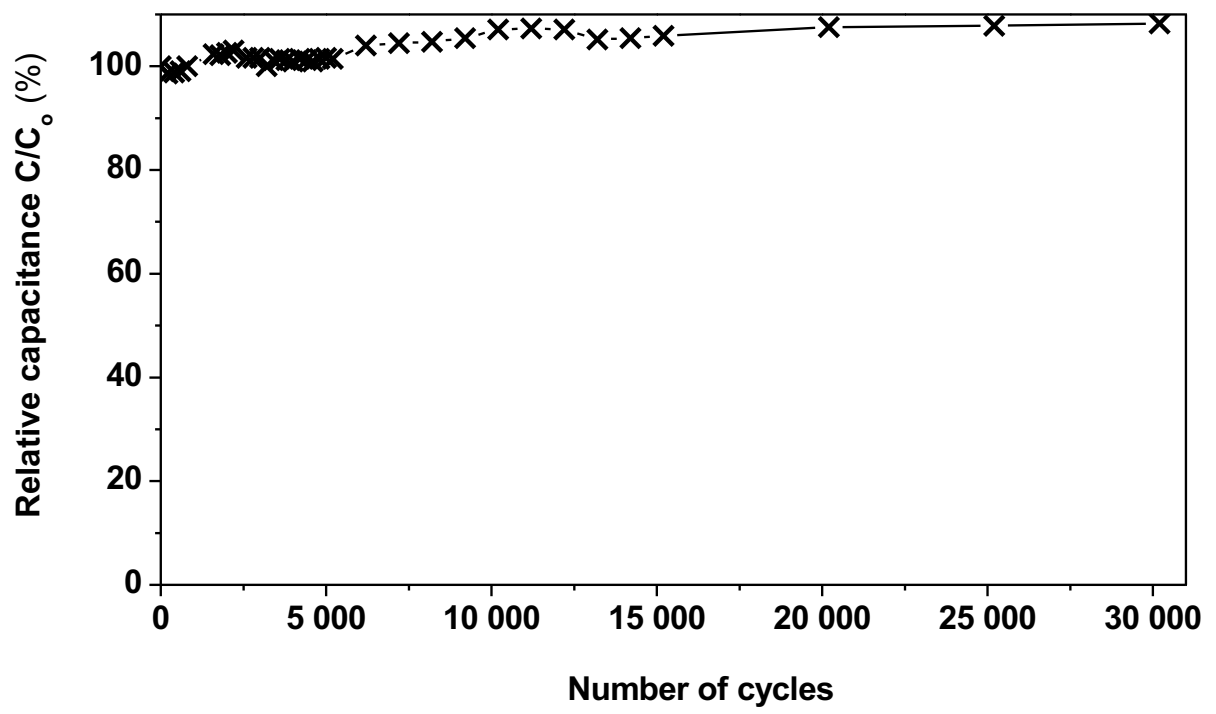

Fig. 6 Evolution of the relative capacitance as a function of the number of electrochemical cycles at $1 \mathrm{~V} \mathrm{~s}^{-1}$ for a MWCNTs-based micro-supercapacitor $\left(\mathrm{C}_{0}\right.$ refers to the capacitance obtained for the first cycle). 